\title{
Measuring temperament in rhesus macaques: consistency and change in emotionality over time
}

\author{
Dario Maestripieri ${ }^{\mathrm{a}, \mathrm{b}}$

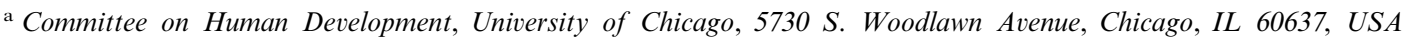 \\ b Yerkes Regional Primate Research Center, Emory University, Atlanta, GA, USA
}

Received 8 December 1999; received in revised form 7 March 2000; accepted 10 March 2000

\begin{abstract}
This study of rhesus macaques (Macaca mulatta) investigated whether individual differences in emotionality, as measured by scratching frequencies, are stable over time and across seasons. Five adult females living in captive social groups were observed during two consecutive birth seasons and five females during the birth and the mating season. Scratching frequencies were higher during the birth than during the mating season, suggesting that the presence of infants was associated with elevated emotionality. Individual differences in scratching frequencies remained stable across two consecutive birth seasons, but there was no significant correlation between scratching frequencies in the birth and in the mating season. These findings suggest that, under certain circumstances, individual differences in emotionality are consistent over time and that scratching may be used as a non-invasive indicator of temperament. (C) 2000 Elsevier Science B.V. All rights reserved.
\end{abstract}

Keywords: Emotionality; Temperament; Displacement activities; Macaques

\section{Introduction}

In recent years, there has been a growing interest in drawing inference on cognitive processes and emotional states from animal behavior. While in humans the study of emotion and cognition has often proceeded in parallel (e.g. Izard, 1993), research on animal emotion has lagged far behind that on cognition. One reason for this discrepancy

E-mail address: dario@ccp.uchicago.edu (D. Maestripieri) is that the recent development of sophisticated empirical procedures for investigating animal cognition in the field and in the laboratory (e.g. Ristau, 1991; Tomasello and Call, 1997) has not been accompanied by parallel progress in the objective and quantitative assessment of animal emotion. For example, although in a number of species differences in personality or temperament are increasingly being invoked to account for interindividual variability in social behavior or cognitive performance (goats: Lyons et al., 1988; fish: Francis, 1990; octopuses: Mather and Ander-

0376-6357/00/\$ - see front matter (C) 2000 Elsevier Science B.V. All rights reserved.

PII: S0376-6357(00)00083-8 
son, 1993; bushbabies: Watson and Ward, 1996; hyenas: Gosling, 1998), assessment of emotionality is, for the most part, still based on subjective ratings (e.g. Bolig et al., 1992; Gosling, 1998).

In nonhuman primates such as macaques and chimpanzees, displacement activities such as scratching and autogrooming have proved to be a useful tool for quantitatively investigating emotional changes associated with social interactions (Diezinger and Anderson, 1986; Maestripieri et al., 1992). Displacement activities, and in particular scratching, are likely to reflect tension or anxiety associated with motivational conflict or anticipation of danger. For example, scratching increases in frequency in anxiety-eliciting situations such as being in close proximity to a high ranking individual (Pavani et al., 1991), following aggression (Aureli and van Schaik, 1991), or during momentary separation from young offspring (Maestripieri, 1993). Moreover, in macaques, scratching frequencies are selectively increased by anxiogenic drugs and reduced by anxiolytics (Schino et al., 1996).

Although rapid changes in scratching frequencies appear to reliably reflect changes in emotional states associated with social interactions, the question of whether individual differences in overall scratching frequencies reflect stable differences in emotionality has not yet been investigated. Since temperament can be defined as consistency in emotional responsiveness to challenging situations (e.g. Clarke and Boinski, 1995), evidence that individual differences in frequencies of scratching remain relatively stable over time and across situations would suggest that scratching can be a good indicator of differences in temperament.

In the present study, I investigated whether scratching can provide information on the temperament of female rhesus macaques by comparing their frequencies of scratching in different years and in similar or different circumstances, namely during the birth season and the mating season. Two predictions were tested: first, that scratching rates should be higher during the birth season than during the mating season; and second, that there should be a positive correlation between the frequencies with which females scratch themselves in different periods of time, irrespective of season. The rationale for the first prediction is that the overall frequency of scratching in a certain period of time should reflect the general level of anxiety experienced by an individual during that period, and that female anxiety should be higher during the birth season because of the presence of young infants (see Maestripieri, 1993; one could argue that mating interactions may also be accompanied by increased anxiety but there is no empirical evidence that this is the case). The rationale for the second prediction is that if individual differences in scratching frequencies reflect differences in temperament, they should remain stable over time and irrespective of quantitative changes in scratching across seasons.

\section{Materials and methods}

Study subjects were ten adult rhesus macaque females living in three social groups at the Field Station of the Yerkes Regional Primate Research Center in Lawrenceville, GA. The groups were housed in outdoor compounds $(35 \times 35 \mathrm{~m})$ with attached indoor quarters. Each group was composed of two to five adult males and 32-35 adult females with their subadult, juvenile, and infant offspring. Total group size ranged between 66 and 98 individuals. All subjects were born in the groups in which they lived and group composition did not change significantly during the study period. All animals were fed twice a day (at 08:00 and 16:00 h) and water was freely available.

Scratching data were collected during a series of studies of maternal and social behavior. Five subjects were first observed for 12 weeks during the birth season (April-July) of 1993 and then for 6 weeks during the mating season (October-December) of 1995 (birth-mating subjects, or BM). Five subjects were observed for 12 weeks during the birth season of 1996 and for another 12 weeks during the birth season of 1997 (birth-birth subjects, or BB). For all subjects, observations during the birth season were conducted with the focal animal sampling technique in four 30-min weekly sessions. Observations during the mating season were conducted with the focal animal sampling technique in three weekly 20 -min sessions. Thus, 
for the BM subjects, $24 \mathrm{~h}$ of observation were available for the birth season and $6 \mathrm{~h}$ for the mating season, while for the BB subjects, $24 \mathrm{~h}$ of observation were available for each birth season. All observations were randomly distributed between 08:00 and 19:00 $\mathrm{h}$ and made from a platform that provided an unrestricted view of the entire compound. Data were collected with a portable computer. All subjects had newborn offspring during the birth seasons in which they were observed.

Data analysis focused on the mean frequency (number of scratching episodes per hour) with which subjects scratched themselves. Tests were two-tailed, unless otherwise specified. $P<0.05$ was considered statistically significant.

\section{Results}

A mixed-design ANOVA with repeated measures indicated that the frequencies of scratching of the five BM subjects did not differ from those of the five BB subjects $(F 1,8=0.17$, NS). The scratching frequencies recorded during the second period (birth or mating season) were significantly lower than those recorded during the first birth

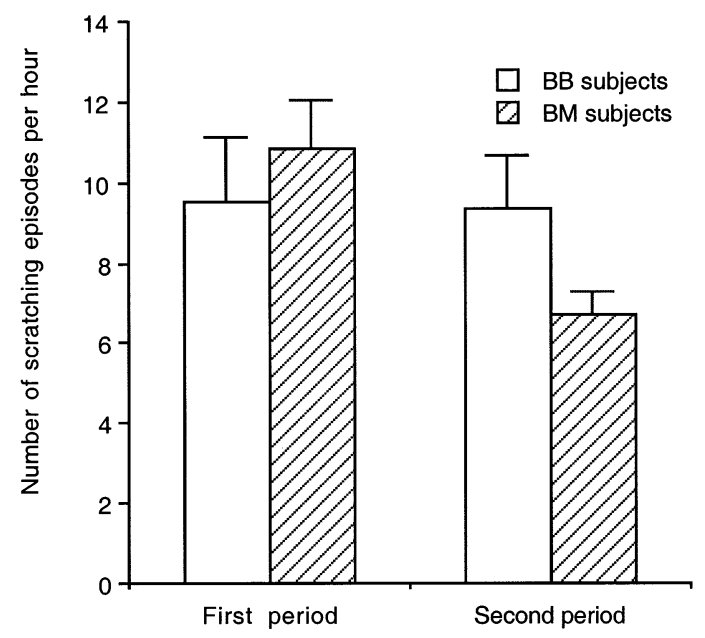

Fig. 1. Mean $(+$ SEM) frequencies of scratching per hour per individual during two observation periods: two consecutive birth seasons for $\mathrm{BB}$ subjects and the birth and the mating seasons for BM subjects. season $(F 1,8=10, \quad P<0.02$, Bonferroni-Dunn post-hoc test, $P<0.05)$. Moreover, there was a significant interaction between subject identity and observation period $(F 1,8=8.62, P<0.05)$, due to the fact that for the BM subjects, the frequencies of scratching recorded during the mating season were significantly lower than those recorded during the birth season (post-hoc test, $P<0.05$, one-tailed; Fig. 1), whereas the frequencies of scratching of the BB subjects were not significantly different in the two birth seasons (post-hoc test, NS). Thus, the decrease in scratching frequency during the second observation period was mainly due to a decrease in scratching during the mating season for the BM subjects.

The individual frequencies of scratching recorded during the first and the second observation period were significantly correlated for the BB subjects (Spearman's correlation, $r=0.9, N=$ 5, $P<0.05$, one-tailed; Fig. 2a), but not for the BM subjects $(r=0.5, N=5$, NS; Fig. 2b). Thus, the subjects observed in the two birth seasons were very consistent in the frequency with which they scratched themselves whereas such consistency was not observed across the birth and the mating season.

\section{Discussion}

This study of rhesus macaques suggests that individual differences in emotionality can be consistent over time but not necessarily across different situations. As predicted, scratching frequencies during the birth season were higher than those during the mating season, suggesting that motherhood is associated with elevated emotionality. This finding is consistent with those of previous studies showing that the presence of infants can be a source of considerable anxiety for rhesus mothers (e.g. Maestripieri, 1993). Moreover, individual differences in scratching frequencies observed during one birth season were very consistent with those observed in the next birth season. This finding suggests that differences in motherhood-related emotionality are consistent over time and lends support to the hypothesis that scratching can be a good indicator of tempera- 

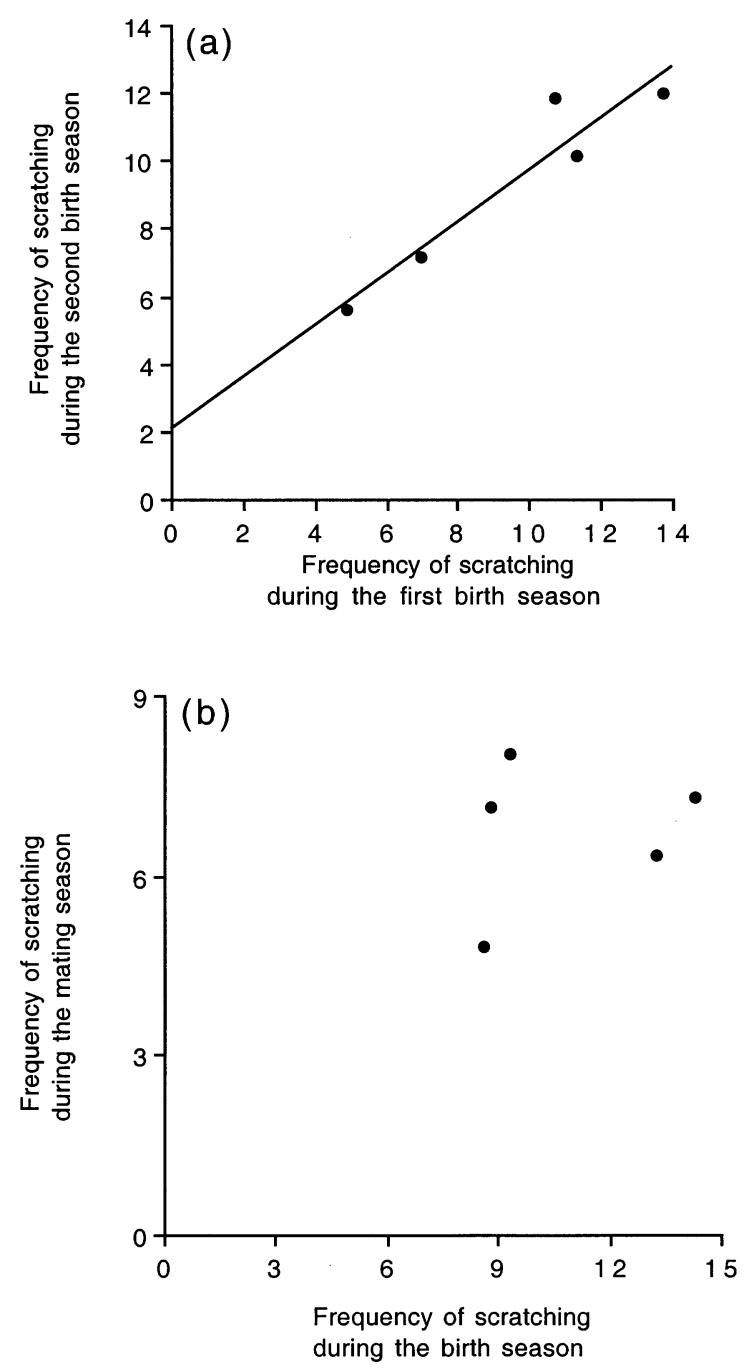

Fig. 2. (a) Correlation between frequencies of scratching of BB subjects during two consecutive birth seasons. (b) Correlation between frequencies of scratching of $\mathrm{BM}$ subjects during the birth and the mating season. Data are mean values per hour for each individual.

ment. The temperament hypothesis, however, also predicted that individual differences in scratching frequencies should be consistent across seasons, whereas this was not the case in this study.

The lack of correlation between scratching frequencies in the birth and in the mating season could be interpreted in different ways. First, it may have resulted from the fact that, whereas for the BB subjects data were collected in two consecutive birth seasons, for the BM subjects the mating season data were collected 2.5 years after the birth season data. Thus, it may be argued that individual differences in scratching frequencies do reflect differences in temperament but that such differences are not stable over long periods of time. Second, it is possible that consistent individual differences in temperament are only observed across periods of time or situations that are associated with similar levels of stress (e.g. two motherhood experiences). If this were the case, one would expect a correlation between individual scratching rates displayed in two different anxiety-eliciting situations such as separation from the offspring or following aggression but not necessarily between scratching levels measured under stress and in baseline conditions. Finally, it cannot be ruled out that overall scratching frequencies may vary across seasons in relation to environmental factors (e.g. ambient temperature or parasite load; see Pavani et al., 1991) and that individuals are differentially sensitive to these factors, thus confounding the relation between scratching and temperament.

Since the correlation between individual scratching frequencies in different birth seasons provides evidence that rhesus macaques show some stability in their emotionality, the relationship between temperament and scratching should be further investigated in future studies comparing individuals, not only across different periods of time, but also different social situations within the same period of time. Moreover, it would be important to consider, along with scratching, other behavioral or nonbehavioral indicators of emotional responsiveness such as heart rate or cortisol levels (e.g. Sapolsky, 1990; Clarke et al., 1994). If individual differences in scratching frequencies across stressful situations are correlated with differences in heart rate or cortisol, this would further validate the use of scratching as a non-invasive and easy-to-record indicator of temperament and provide an important tool for the study of interindividual variability in primate behavior and its determinants. 


\section{Acknowledgements}

I thank Michelle Tomaszycki for help in data collection. This work was supported by NIMH grant R01-MH57249, and in part by NIH grant RR-00165 to the Yerkes Center. The Yerkes Center is fully accredited by the American Association for Accreditation of Laboratory Animal Care.

\section{References}

Aureli, F., van Schaik, C.P., 1991. Post-conflict behaviour in long-tailed macaques: II. Coping with the uncertainty. Ethology 89, 101-114.

Bolig, R., Price, C.S., O’Neill, P.L., Suomi, S.J., 1992. Subjective assessment of reactivity level and personality traits of rhesus monkeys. Int. J. Primatol. 13, 287-306.

Clarke, A.S., Boinski, S., 1995. Temperament in nonhuman primates. Am. J. Primatol. 36, 1-23.

Clarke, A.S., Mason, W.A., Mendoza, S.P., 1994. Heart rate patterns under stress in three species of macaques. Am. J. Primatol. 33, 133-148.

Diezinger, F., Anderson, J.R., 1986. Starting from scratch: a first look at a 'displacement activity' in group-living rhesus monkeys. Am. J. Primatol. 11, 117-124.

Francis, R.C., 1990. Temperament in a fish: a longitudinal study of the development of individual differences in ag- gression and social rank in the Midas cichlid. Ethology 86, $311-325$.

Gosling, S.D., 1998. Personality dimensions in spotted hyenas (Crocuta crocuta). J. Comp. Psychol. 112, 107-118.

Izard, C.E., 1993. Four systems for emotion activation: cognitive and noncognitive processes. Psychol. Rev. 100, 68-90.

Lyons, D.M., Price, E.O., Moberg, G.P., 1988. Individual differences in temperament of domestic dairy goats: constancy and change. Anim. Behav. 36, 1323-1333.

Maestripieri, D., 1993. Maternal anxiety in rhesus macaques (Macaca mulatta). I. Measurement of anxiety and identification of anxiety-eliciting situations. Ethology 95, 19-31.

Maestripieri, D., Schino, G., Aureli, F., Troisi, A., 1992. A modest proposal: displacement activities as an indicator of emotions in primates. Anim. Behav. 44, 967-979.

Mather, J.A., Anderson, R.C., 1993. Personalities of octopuses (Octopus rubescens). J. Comp. Psychol. 107, 336-340.

Pavani, S., Maestripieri, D., Schino, G., Turillazzi, P.G., Scucchi, S., 1991. Factors influencing scratching behaviour in longtail macaques. Folia Primatol. 57, 34-38.

Sapolsky, R.M., 1990. Adrenocortical function, social rank, and personality among wild baboons. Biol. Psych. 28, $862-878$.

Schino, G., Perretta, G., Taglioni, M., Troisi, A., 1996. Primate displacement activities as an ethopharmacological model of anxiety. Anxiety 2, 186-191.

Ristau, C., 1991. Cognitive Ethology. Erlbaum, Hillsdale, NJ.

Tomasello, M., Call, J., 1997. Primate Cognition. Oxford University Press, Oxford.

Watson, S.L., Ward, J.P., 1996. Temperament and problem solving in the small-eared bushbaby (Otolemur garnettii). J. Comp. Psychol. 110, 377-385. 